Fall 2006

\title{
Putting 'culture' back in multicultural education: A Call for a critical and interdisciplinary approach to teacher education
}

\author{
Pepi Leistyna \\ University of Massachusetts Boston
}

Follow this and additional works at: https://digitalscholarship.unlv.edu/jpme

\section{Repository Citation}

Leistyna, Pepi (2006) "Putting 'culture' back in multicultural education: A Call for a critical and interdisciplinary approach to teacher education," Journal of Praxis in Multicultural Education: Vol. 1: No. 1, Article 1.

DOI: $10.9741 / 2161-2978.1015$

Available at: https://digitalscholarship.unlv.edu/jpme/vol1/iss1/1

This Article is protected by copyright and/or related rights. It has been brought to you by Digital Scholarship@UNLV with permission from the rights-holder(s). You are free to use this Article in any way that is permitted by the copyright and related rights legislation that applies to your use. For other uses you need to obtain permission from the rights-holder(s) directly, unless additional rights are indicated by a Creative Commons license in the record and/ or on the work itself.

This Article has been accepted for inclusion in Journal of Praxis in Multicultural Education by an authorized administrator of Digital Scholarship@UNLV. For more information, please contact digitalscholarship@unlv.edu. 


\section{Putting 'Culture' Back in Multicultural Education: A Call for a Critical and Interdisciplinary Approach to Teacher Education}

\section{Pepi Leistyna}

In this era when public educators are faced with endless credentialing, certification, standardization, and accountability schemes, one crucial component that is readily and often strategically neglected in teacher education programs throughout the United States is having teachers and administrators, through analysis of their own experiences and exposure to literature and research from multiple disciplines, theoretically engage the complexities of culture and the politics of cultural production.

I know that with my own professional development at the Harvard Graduate School of Education, where I completed my Masters and Doctorate in the 1990s, I was actually deterred from exploring the kinds of theory and research that make critical analysis of culture and cultural politics fundamental to the educational process. This is not surprising considering that many of the faculty members themselves regarded critical social theory with disdain. One professor, who considered himself to be progressive, dismissed one of my papers in front of the class as:

This is a lot of big words! The use of deconstruction sounds like a lot of masturbation to me.

With a single statement, he negated, without ever having engaged the strengths and weaknesses therein, one of the twentieth century's most important movements in literary criticism-Jacques Derrida's work in deconstructionism. Not only did this response attempt to dismiss the significance of such work, but it also functioned to inhibit students from developing a more interdisciplinary approach to education, that is, from critically appropriating and reinventing educational insights from across the social sciences.

In another course on literacy in Latin America, the syllabus altogether ignored the work of renowned, Brazilian educator Paulo Freire. Again, this came as no surprise given that the professor who taught the class publicly declared, "I can't read Freire, he makes me clam!”

Pepi Leistyna is an Associate Professor of Applied Linguistics Graduate Studies at the University of Massachusetts Boston, where he coordinates the research program and teaches courses in cultural studies, media literacy, and language acquisition. 
Often, faculty (and as an unfortunate consequence students) make claims to scientific objectivity (i.e., positivism) as a means to discourage substantive debates over such pressing issues as white supremacy, patriarchy, and neoliberalism, and to disconnect social agency-one's ability to act-from education. For example, in an attempt to shape the way that I would respond to a paper about the culture of schools, one professor wrote, "You do a bit better this time, but your particular political agenda has lowered the quality of this paper." Another faculty member wrote, in a letter of recommendation:

His papers have all been at least excellent, and several have been superlative. The most recent one set out to reconcile Chomsky's language module with a relativistic stance on language and thought, and it was a well though-out, richly informed try. Pepi's only weakness as a scholar...is to become so exercised about matters of social justice that analysis threatens to turn to rhetoric.

In the few courses that dealt with the social nature of learning, theory was in fact limited to cultural relativism and thus to a superficial understanding of cultural similarities and differences. The basic idea embraced in such classrooms is that if we could only recognize and be sensitive to culturally driven cognitive and communicative differences everything would be okay in the classroom, and with the world.

Throughout my graduate experience, there was a general unwillingness to engage the complex interrelationships among culture, identity, and social reality. In the end, this type of pedagogy serves to fragment and disarticulate experience not only from its socio-historical and ideological construction, but also from the relationships of power within which these systems of meaning, identities, and conditions emerge. However, such disarticulation is not surprising in a school of education that housed its courses in literacy and language acquisition in the Department of Human Development and Psychology with very little connection to the Department of Learning and Teaching - as if the reason that millions of people in this country are illiterate has to do predominantly with cognitive, internal processes rather than the unequal and abusive relations of power and oppressive practices that give rise to the antagonistic cultural climate of the classroom and the greater society.

In fact, fragmentation of knowledge is the norm in most universities. In my own experience, a prevailing rebuttal among faculty to critical and interdisciplinary comments was, "That's not education, that's politics." This fragmentation of disciplines not only serves to deter young educators from developing an interdisciplinary view of the world, but it also encourages them to deny the inherently political nature of education and to disregard critical work altogether. I can't count how many times my ideas were curtly dismissed as "Marxist" or "Communist". What's important to note here is that markers such as these were not used as intellectual invitations for debate, given that most people in the United States have never read Karl Marx - and this is certainly not part of their intellectual exposure in graduate school. If they had been exposed to such work they would have understood from the get go that critical social theory 
has moved way beyond the confines of Marx's reductionistic and deterministic view of history based on material/class struggle (historical/dialectical materialism). This is precisely the point of this paper: Those educators who are truly interested in culturally responsive teaching, democratizing public education, and realizing social justice need to be introduced to the vast history of interdisciplinary work that explicitly explores-exposes them to, not imposes on them-cultural politics so as to better prepare them for the cultural realities and diversity that they will experience in institutions of public education. Without this background and bereft of the tools of critical social theory, even wellintentioned educators who embrace multicultural education find themselves limited in their scope and impact.

The Pitfalls of Multicultural Education When the Relationship between Culture and Power Goes Unaddressed

Within mainstream models of multicultural education, the term culture is usually used to refer to select group practices and material artifacts abstracted from the sociohistorical, economic, and political conditions that give rise to such phenomena. On the contrary, critical social theory views culture as a terrain of lived experiences and institutional forms organized around diverse elements of struggle and domination. In other words, culture embodies the lived experiences and behaviors that are the result of the unequal distribution of power along such lines as race, gender, ethnicity, class, and sexual orientation. As people interact with existing institutions and social practices in which the values, beliefs, bodies of knowledge, styles of communication, and biases of the dominant culture are imposed, they are often stripped of much of their power to articulate and realize their own goals (Leistyna, Woodrum \& Sherblom, 1996). For example, efforts in the United States to enforce a "common culture" (an un-negotiated foundation of values, ethics, meaning, history, and representation - "our cultural heritage") or "common sense" (a selective view of social reality in which difference is understood as deviant or a deficit), or an English-only agenda are in fact the imposition of an homogenizing social paradigm that grossly limits the possibility for a critical multicultural democracy. The important question is: Whose realities and interests are defining what it means to be American? This question should always call into play relationships of power.

If educators truly hope to democratize their schools and make significant changes in their communities it is important to develop a critical and flexible multicultural philosophy that permeates all aspects of the educational process. But even well-intentioned educators, in their efforts to accomplish this goal, are often greatly limited by the lack of exposure in their own professional development to theory and theorizing around cultural politics.

This was precisely the case in my 8-year study of the Changeton Central Steering Committee's (CSC) efforts to conceptualize and implement a system-wide multicultural education program in their school district. With support from the top brass to develop the program, the CSC (made up of volunteer faculty, counselors, administrators, and aides) knew that multicultural 
education should be concerned with and effect professional development, curriculum and instruction, the hiring process, and community outreach.

However, throughout this longitudinal study, the meaning of culture proved to be a major point of ambiguity for the committee. While culture appeared to have different meanings among CSC members (many of whom, as Christine Sleeter and Carl Grant (1988) foreshadowed in their own research, seemed to equate the word with race and ethnicity), individual conceptualizations were never clearly articulated and there was consequently never an agreed upon group definition of the term. Without a clear working definition, and moving forward from what proved to be an extremely limited understanding of cultural politics, it was inevitable that the CSC would experience great difficulty and confusion in their endeavor to define and design a multicultural education program that would actually have an impact.

The committee had a hard time categorizing what would and wouldn't be considered a cultural group, and thus they had a difficult time deciding who to include and in their efforts. This kind of confusion lead to Carl's contradicting comments: "Don't the Handicapped, or what do you call them-challengedhave a culture?", and, "Women and the handicapped are supposed to be in the curriculum but cultures aren't." Giselle added to this theoretical entanglement by stating:

We should have concerns for all forms of diversity, but we should give the highest priority to cultural issues... We need to include gender and handicap, though they are not the problem-I would like our committee to deal more specifically with cultural and ethnic diversity...

After Carl mentioned "Gays," Giselle insisted, "That is not what is bothering Changeton, cultures are not living together."

Theoretically ill-prepared, the committee, while well-intentioned and sincerely concerned with bettering the lives of all students, virtually neglected the reality that so many people in their community are forced to deal with conditions in which they are stripped of their voices and relegated to the margins of political and economic power. Even the CSC's discussions of race and ethnicity did not engage the realities of racism and white supremacy. Instead, the idea of culture and multiculturalism, as illustrated in one of their Mission Statement's clauses, was reduced to a "celebration of our diversities".

The CSC attempted to address issues of cultural diversity by focusing on sensitizing educators to differences and making classroom curricula more inclusive of all backgrounds. They figured that in this way they could resolve intergroup antagonisms and consequently all students would get along and achieve academically. Overall, the committee was working towards "acceptance," "appreciation of all cultures," and being "inclusive," with the idea that "a celebration of diversities promotes unity."

This depoliticized notion of culture made its way into district curricula which included lessons and events centered on such things as leprechaun traps, Japanese doll day, flag displays, and Chinese New Year. The committee never posed the more difficult questions, nor were they encouraged to by the 
professional organizations that were helping the group develop in-service programs, about the relationship among violence, oppression, poverty, racism, and culture; for example, what it is like to survive in a dilapidated housing project in Changeton where violence and hunger are everyday realties. They didn't explore what students shared with me about what it means to take care of sick parents, the feeling of having no school books, the ramifications of not trusting public education, what it like to be mistreated by teachers, the feeling of having your imprisoned brothers' faces posted around town, the experience of seeing battery acid poured all over someone's head because of a bad 'business' transaction, finding your mother's boyfriend dead in your house from an overdose of drugs, or what it feels like to get stabbed or shot or beaten by the police.

If well-intentioned teachers want to create culturally responsive models, that link the home life to schooling, they are compelled to engage in the actual conditions within which people live. The reality is that many of the people that face extreme obstacles in public schools in this country have been here for generations-Blacks, Native Americans, Native Hawaiians, Chicano/as, Puerto Ricans, women, Gays and Lesbians, the poor, the disabled, and so forth. These are not histories of immigration, but rather, they are the products of such engineered forces as enslavement, conquest, and systematic exclusion.

Some critics may argue that the reason that the majority of multicultural activities that the Changeton schools offered were about food and fun is that they were being served up to children: the idea being that elementary school children are too young to be exposed to hard and painful issues such as racism and poverty. However, the reality is that many youth already know what it's like to hear about some kid shooting a classmate. As Roberto, a former student who left school, testified, "Man, the playground we call the dead ground..." Many children have experienced what it's like to be ignored because they don't yet speak English, not to be invited to birthday parties and sleep-overs because of the color of their skin or their religion, to witness domestic violence, to be evicted from their home, to lose a family member or friend to illness, murder, drinking and driving, suicide, or a drug overdose; or to be hungry. Many have an experiential sense of being sexually molested, bullied, rolling the halls alone in a wheelchair, being called a freak because they don't fit in, being considered ugly or overweight, walking grounds littered with trash, or seeing violence and sex on TV. In addition, great numbers of children have been stigmatized by being in Special Education, Bilingual and English as a second language programs, lower academic tracks, and free lunch programs. The sad reality is that kids at a very early age are racialized, sexualized, gendered, and marked by social class. Here are just a few of the names that I overheard young people in Changeton schools, $\mathrm{k}-5$, referring to each other as: spic, nigger, Jew boy, towel head, camel jockey, chink, cracker, white trash, fag, queen, dyke, pussy, hoochie mama, slut, bitch, nappy hoe, four eyes, cripple, gimp, and project rat.

The CSC was right to insist that they get to students in their early years. As Carl exclaimed, "This is where it begins!" However, in order to effectively achieve consciousness among the very young, we need to move away from the 
idea that children exist in an abstract age of innocence and instead actually engage them, with appropriate discourses, in the social relations and bodies of knowledge that they are readily exposed to in their everyday lives. This is precisely why we need to get to educators early on in order to prepare them for this kind of theoretical and practical work.

\section{Teacher Education}

Teacher education must go beyond the acceptance of differences and Help teachers analyze the sociopolitical system that gives rise to those differences...

(Ana Maria Villegas, 1988, p. 261).

As a democracy, we need to advocate for critical multicultural teacher education programs that expose future teachers and administrators to the issues that they will face in public institutions of learning, helping them to develop their own political awareness and critical theories necessary for transformational praxis. But this won't come to fruition by simply bringing together a diverse group of educators and assuming that because they have the best of intentions or know what it feels like to be discriminated against necessarily leads to an understanding of what oppression means, what causes it, and therefore how to redress such injustice. In fact, a recurring problem with representation of this sort (i.e., "we have a diverse committee") is that experience is often left at the level of description - that is, narratives (what happened) are welcomed at the expense of theoretical analysis (why and how it happened). Such an atheoretical posture gives the erroneous perception that subject position-the place that a person occupies within a set of social relationships shaped by such factors as social class, gender, race, religion, and sexual orientation - is inherently linked to critical consciousness. In other words, when a person shares the pains of social injustice, this narration, in and of itself, is thought to necessarily bring about the intra- and interpersonal political understanding of such oppressive acts. Peter McLaren (1995) warns of this pitfall:

Either a person's physical proximity to the oppressed or their own location as an oppressed person is supposed to offer a special authority from which to speak....Here the political is often reduced only to the personal where theory is dismissed in favor of one's own personal and cultural identityabstracted from the ideological and discursive complexity of their formation

(125).

Countering this tendency to conflate location and consciousness, teacher education programs should be encouraged to nurture the kinds of critical, inclusive dialogue that work to explain/theorize why everyone involved think a particular experience has occurred so as to be able to act in solidarity to change any and all unjust material, political, and symbolic conditions that produced it.

In other words, in order to understand and confront the oppressive values and beliefs that have long informed mainstream social practices, and 
continuously forge and work to secure economic and political rights, schools of education should help to prepare teachers and administrators to think through the complexities of culture by making better use of the synergy that exists among theory, research, and activism. There are a number of important interdisciplinary areas of analysis, where culture is primary, that are generally found outside of the field of education that are very important in achieving such a goal. The following are just a few of the historically important avenues that are generally neglected by schools of education and professional development organizations.

\section{The Frankfurt School}

Conducting extensive ideological critique in order to understand the uses and abuses of power so as to be able to transform them was the task of a group of German intellectuals who were part of what became known as the Frankfurt School (Institut fur Sozialforschung — the Institute for Social Research), founded at the University of Frankfurt, Germany in 1923. This think tank was, until 1933 with the rise of Adolph Hitler, the intellectual home to many influential thinkers who pioneered the systematic analysis of mass-mediated culture and communications and worked to reveal how the 'culture industry' co-opts society and reinforces capitalist social relations-what became better known as critical theory. The word 'critical' implied a break from the limits of positivism and drew on Marx's earlier call for philosophers to change the world rather than simply interpret it.

Interdisciplinary in its approach to understanding domination and the interconnections among economics, politics, culture, psychology, and technology, members of the Frankfurt School explored how the irrationalism and alienation embedded in capitalism and Western civilization work to defuse and disarm any possibility for revolution. Their analyses of authoritarianism and the irrational behavior that permeated the industrialized society in which they were living were largely influenced by the critical philosophy of Immanuel Kant (his ideas on reflection, how to explore the conditions that produce a particular phenomenon, and moral autonomy), G.W.F. Hegel's dialectical method of negation and contradiction, Marx's analysis of the role of ideology in reinforcing the capitalist system, Sigmund Freud's work in psychoanalysis, and Max Weber's critique of rationalism and bureaucratic domination in capitalist societies.

For decades, critical theory has provided researchers and activists with profound insights about the structures and formative powers of society and culture, and how to access the liberatory possibilities of knowledge and revolutionary agency. As a consequence, the complex, interdisciplinary, and diverse perspectives of critical theorists continue to this day to inform social thought, research, and action.

\section{Anti/Post-Colonial Theories}

The study of culture, domination, and liberatory practices has been greatly advanced by anti-colonial, anti-racist thinkers and activists. These 
revolutionaries, also influenced by Marxist and neo-Marxist theories, and psychoanalysis, were fighting (and continue to fight) against a long history of global colonialism and white supremacy. They understood that economics and politics are important forces in maintaining unequal relations of power in society, but they also recognized the power of culture and the central role of ideology in working to control the psyche of people, public opinion, and consequently in maintaining systems of oppression. For these activists, all cultural terrain is worth fighting over. If it weren't, then colonizers and fascists alike wouldn't immediately go after schools, media, and other public spheres that produce and disseminate knowledge.

Concerned with how the colonizer and the colonized are represented, how subordinated knowledge is produced and circulated, the ways in which oppression gets internalized, and the power of resistance and opposition, these revolutionaries have provided theoretical frameworks for confronting the ideologies, authority, and social relations that have driven the oppressive legacy of colonialism and imperialism, and they have inspired liberation movements around the world for decades.

\section{Poststructural and Postmodern Frameworks}

Poststructuralists have also been interested in understanding the power/knowledge configuration. By no means a monolithic group, many of these theorists have argued that consciousness, identity, meaning, and cognitive development are social constructions - the central idea being that systems of communication informed by particular values and beliefs play a significant role in shaping human faculties, sensibilities, and subjectivities.

Much more flexible than the hitherto structuralist theorists who were in search of universal processes and mechanisms that could systematically explain meaning and human behavior, the poststructuralists have been engaged in an exploration of how knowledge is constructed within specific social conditions and relations of power. Of particular importance has been the concept discourse, which refers to the way reality is perceived through and shaped by historically and socially constructed ways of making sense-that is, languages, and systems of meaning, and practices that order and sustain particular forms of social existence.

Poststructuralism, and its cognitive and cultural turn toward language, affect, consciousness, and systems of meaning, would theoretically pave the way for the emergence of postmodernism. Postmodernists, have great disdain for positivism, instrumental reason, and any other paradigm that subsumes every aspect of social reality into one totalizing theory-that is to grand or master narratives. Universals in the form of absolute truth, certainty, and objectivity are cast aside in the name of heterogeneity, contingency, intersubjectivity, and indeterminacy.

Recognizing the existence of multiple realities, identities and voices, and the need for reflexivity among researchers, activists influenced by poststructural and postmodern theory have worked to create spaces within which subaltern voices can emerge under their own volition. Because of their 
invaluable contributions to social theory, especially around issues of identity and difference, poststructuralism and postmodernism have been readily appropriated from, expanded upon, and used to inform a wide range of political movements including feminism, queer rights, and what's referred to as the new ethnography —research that is clearly directed towards social change.

\section{Cultural Studies}

Cultural studies has been primarily occupied with how meaning is produced, circulated, legitimated, and consumed in society, and how relations of power affect this complex and multidirectional process. As such, it too has had major political implications. In fact, its roots in the Centre for Contemporary Cultural Studies at the University of Birmingham, founded in England in 1964 by Richard Hoggart (popularly known as the Birmingham School), were directly connected to political projects. The primary figures understood theory as being strategic, performative, and directed towards solving important pressing economic, social, and political problems.

Institutionally, cultural studies have been used to theorize about how culture and representation shape our lived experiences and sense of political agency. Focused on both the production and consumption of meaning, cultural studies analysts engage literature, popular and mass culture and media, subcultures, and audience reception, looking at both domination and creative resistance and how they are articulated in cultural practices.

The fundamental argument that underlies this study of popular culture is that reality is socially constructed and thus possible to change.

The work of Antonio Gramsci (1891-1937) has had a major impact on the trajectory of cultural studies. Gramsci worked to explain why the oppressed were not revolutionary. This resulted in the reinvention of the ancient Greek concept hegemony, which he used as a point of analysis to examine how the imposition of particular ideologies and forms of authority results in the reproduction of social and institutional practices through which dominant groups maintain not only their positions of privilege and control, but also the consensual support of other members (even those subordinated) of society. Shifting away from Marx's focus on economics, Gramsci looked instead to cultural relations and their effects on politics. He was interested in how, along with the coercive forces of the State, other organizations of civil society such as the family, houses of faith, educational institutions, and so on, often worked in the interests of the ruling class.

Encouraging an exploration of these various camps of thought is by no means a call to simply embrace them at face value. Theorizing demands that we actively engage bodies of knowledge and human practices for the logics and sociohistorical conditions that inform them so that they can be reworked. It encourages individuals to evaluate, based on their own experiences, expertise, and insight, the strengths and weaknesses of any conceptual, empirical, and practical movement and recontextualize and reinvent its possibilities for one's own predicaments (Leistyna, 2005). As an integral part of any political project, theorizing presents a constant challenge to imagine and materialize alternative 
political spaces and identities and more just and equitable economic, social, and cultural relations. It makes possible consciousness raising, coalition building, resistance, activism, and structural change.

In such undemocratic times, it's not surprising that such practice is often discouraged. The assault on limiting access to critical discourses and theorizing is in part connected to ways in which the university has been used as an indoctrinating force to deskill students by working to mold them into uncritical receivers and consumers of existing theory, but rarely viewing them as active and creative participants in the generative process of understanding. This is especially evident as globally the academy is falling prey to the kinds of corporate logic that package thought as a commodity for exchange in the marketplace rather than inspiring the kinds of inquiry that probe that very logic and use of public energy and space (Aronowitz, 2001; Readings, 1997). Within these corporate models of public education the production of technicians in all disciplines (areas of study which are artificially disconnected from one another) comes at the expense of inter/transdisciplinary thinkers and producers of social knowledge about the world. As students are distracted or lured away from critically reading historical and existing social formations, especially those that maintain abuses of power, they often become the newest wave of exploited labor power and reproducers, whether they are conscious of it or not, of oppressive social practices.

As argued throughout this paper, a critical model of multicultural education is primarily concerned with the kinds of theories and practices that encourage students, teachers, administrators, care-givers, and communities to develop an understanding of the interconnecting relationships among ideology, power, meaning, and identity that constitute culture. In other words, Critical Multicultural Education is rooted in a democratic project that emphasizes new theories and languages of critique, resistance, and possibility capable of engaging (critically examining and transforming) the standard academic boundaries and social and educational practices that maintain the de facto social code in the United States. These new theories and languages provide the necessary analytic stepping stones for realizing a truly democratic process through which we can better identify the sociopolitical realities that shape our lives, begin to negotiate our differences, and where necessary, transform our practices. It is the goal of self and social transformation, and not mere reform, which is central to this process. As Donaldo Macedo (1994) argues:

Given the complexity of our rapidly changing multicultural society, reform represents only a cosmetic change, leaving the inherent ideology that informs education unproblematic and unchanged. In reality, what we really need is not reform; what we need is transformation...However, transformation requires not only a thorough analysis of the structure of schooling and the ideology that informs it, but it also necessitates a critical understanding of the interdependence between schooling and the sociocultural and political reality of the society within which schools exist (p. 140). 
Unfortunately, the basic tenets that constitute the core of critical pedagogy of this sort have often been neglected or dismissed within teacher education programs and consequently in mainstream projects of change; which are consequently bereft of the dialogue, insights, and contributions that such perspectives offer. Efforts like those in Changeton, guided by educators who are the product of teacher education and professional development programs, can invite surface reforms, but merely recognizing our differences, and ignoring such related problems as white racism, social injustice, and abuses of power as a broader set of political and pedagogical concerns, will not lead to a transformation of the exclusionary structural and ideological patterns of our unequal society.

What concerned educators need to do from here on out is be encouraged to explore the multiplicity of theoretical and practical insights from across the spectrum of disciplines and established and emerging camps of multicultural education - conservative, liberal, and critical—and to begin the political process of making meaning and becoming transformative agents rather than victims or mere reproducers of existing ideologies. While it's important to recognize that even with these tools of change concerned citizens face great obstacles, the argument being made here is that without them the mission is futile. With a dose of the real world, and a dose of the kinds of critical social theory that make the analysis of culture fundamental to the educational process, educators in my experience as a teacher educator for the past 14 years realize that when it comes to understanding and effecting public education, real praxis - that on-going relationship between critical reflection and action-is fundamental to any vibrant democracy. 


\section{References}

Aronowitz, S. (2001). The Knowledge Factory: Dismantling the Corporate University and Creating True Higher Learning. Boston: Beacon Press.

Freire, P. (1970). Pedagogy of the Oppressed. London: Penguin.

Gibson, M.A. (1976). Approaches to Multicultural Education in the United States: Some Concepts and Assumptions. In Anthropology and Education Quarterly. 7, pp. 7-18.

Leistyna, P. (1999). Presence of Mind: Education and the Politics of Deception. Boulder, CO: Westview.

Leistyna, P. (2002). Defining and Designing Multiculturalism: One School System's Efforts. Albany, NY: SUNY.

Leistyna, P. (Ed.) (2005). Cultural Studies: From Theory to Action. Oxford: Blackwell.

Leistyna, P., Woodrum, A. \& Sherblom, S. (Eds.) (1996). Breaking Free:

The Transformative Power of Critical Pedagogy. Cambridge, MA: Harvard Publishing Group.

Macedo, D. (1994). Literacies of Power: What Americans Are not Allowed to Know. Boulder: Westview Press.

McCarthy, C. (1993). "After the Canon: Knowledge and Ideological Representation in the Multicultural Discourse on Curriculum Reform." In: Race, Identity, and Representation in Education. (Eds.) McCarthy, C. \& Crinchlow, W. New York: Routledge.

McLaren, P. (1995). Critical Pedagogy and Predatory Culture: Oppositional Politics in a Postmodern Era. New York: Routledge.

Pratte, R. (1983). Multicultural Education: Four Normative Arguments. Educational Theory. 33, 21-32.

Readings, B. (1997). The University in Ruins. Cambridge, MA: Harvard University Press.

Sleeter, C. \& Grant, C. (1988). Making Choices for Multicultural Education: Five Approaches to Race, Class, and Gender. New York: Merrill.

Villegas, A.M. (1988). School Failure and Cultural Mismatch: Another View. The Urban Review. 20 ( 4), 258-271.

${ }^{1}$ For a detailed description and analysis of this experience, see the chapter in my book Presence of Mind: Education and the Politics of Deception, "Veritas: The Fortunes of My Miseducation at Harvard".

${ }^{1}$ It is also important, but beyond the scope of this paper, for educators to explore Action Research as it has always had a political and transformative agenda explicitly woven into its theoretical and empirical fabric. Making use of any and all methodological approaches-even creating new ones to address a specific set of conditions, action researchers have focused on how a particular group and its individual members come to know something within the actual struggle to transform it. Because interpretation, meaning-making, accessing the "Other's" experience, and understanding what shapes human consciousness all play such an important role in action-based research, so do the influences of humanistic psychology, interpretivism, social constructivism, hermeneutics, and phenomenology. Educators should also be exposed to Social Movement Research which has enormous political potential. Concerned with the power of movements and their impact on people, public discourse, policy, institutions, and governments, Social Movement Research has looked at the ways in which activists understand and make use of the cracks of agency made possible by shifting economic, political, and cultural relations, and how organizations and networks develop, mobilize, and change. 